Págs. 143-155

\title{
As medidas da educação. Medição e gestão mediante indicadores
}

\author{
Measures of education. \\ Measurement and management through indicators
}

Dietmar K. Pfeiffer ${ }^{1}$

\section{Resumo}

O processo da globalização exerce um impacto forte sobre os sistemas educacionais nacionais no mundo inteiro. Parte deste processo é a implementação de um sistema de indicadores para a mensuração da qualidade educacional. De importância especial neste contexto é a disseminação de avaliações de larga escala (PISA). Medir não é mais uma prática exclusiva para as ciências exatas, mas se tornou em um dos objetivos principais nas ciências educacionais, também. Porém, embora haja uma plentora de indicadores educacionais, uns deles fazendo parte de conhecidos índices (HDI, SESC, ICM), há apenas poucas initiativas até agora para criar um índice composto para o desenvolvimento educacional.

O artigo presente tem como objetivo revisar de forma crítica os problemas de mensurações representativas nas ciências humanas apontando que a maioria dos indicadores compostos e índices não correspondem à axiomática da teoria representacional de medição. Medições mediante índices são consideradas como substitutos para medições representativas. Seus níveis escalares e o significado são muitas vezes desconhecidos de modo que precisam de ser aproximados através de critérios de fiabilidade e validade. A diversidade teórica é considerado como um dos motivos principais para a falta de medidas constistentes e relevantes no campo educacional. Além do mais, muitas variáveis na esfera educacional não são quantificaveis.

A preocupação principal no tocante a medição por indicadores se refere ao caráter ambivalente deles. Por um lado eles podem proporcionar informações relevantes ao nível descritivo e subsidiar decisões politicas, por outro lado, a «cultura de indicadores» assume de forma crescente vertentes de um sistema normativo de controle.

\section{Palavras chaves}

İndice, indicator, medição, PISA, gestão de educação, globalização.

\section{Resumen}

El proceso de globalización ejerce un fuerte impacto sobre los sistemas educativos nacionales de todo el mundo. Parte de este proceso es una implementación de un sistema de indicadores para la medida de la calidad educativa. En este contexto adquiere una especial importancia la difusión de evaluaciones de larga escala (PISA). Medir ya no solo no es una práctica exclusiva de las ciencias exactas, sino que también devino uno de los objetivos principales de las ciencias educativas. Pero, aunque hay un abanico de indicadores educativos, algunos de ellos formando parte de índices conocidos (HDI; SESC, ICM), hasta ahora apenas hay unas pocas iniciativas para crear un índice compuesto para el desarrollo educativo.

El presente artículo tiene como objetivo revisar de forma crítica los problemas de las mediciones representativas en las ciencias humanas señalando que la mayoría de los indicadores compuestos e índices no corresponden a la axiomática dela teoría representativa de la medición. Sus niveles de escala y sus significados son muchas veces desconocidos, de modo que necesitan ser abordados a través de criterios de fiabilidad y valide. Una diversidad teórica es considerada como uno de los motivos principales para la falta de medidas consistentes y relevantes en el campo educativo. Además, muchas variables en la esfera educativa no son cuantificables.

Una preocupación principal respecto a la medición a través de indicadores se refiere a su carácter ambivalente. Por un lado, pueden proporcionar informaciones relevantes a nivel descriptivo y avalar decisiones políticas, por otro lado, una «cultura de los indicadores» asume de forma creciente aspectos de un sistema normativo de control.

\section{Palabras clave}

Indice, indicador, medición, PISA, gestión educativa, globalización.

\footnotetext{
1 Universität Münster, Alemania, dicape@uni-muenster.de
} 


\section{Abstract}

The process of globalization exerts an increasing impact on national educational systems worldwide. Part of this process is the attempt to establish an indicator system for educational quality measurement. Of outstanding importance in this context is the dissemination of large scale assessment studies (PISA). Measuring is not any longer a practice of natural sciences only, but has become a main objective in educational sciences as well. But although there are a plethora of educational indicators, some of them making part of well-known indexes (HDI, ESCS, GCI) there are up to now only few attempts to create a composite index for educational development.

The present article aims to review critically the problems of representative measurement in human sciences pointing out, that most of the indicators and indexes do not fit the axiomatic of the representational theory of measurement. Index measurement must be considered as a substitute for representative measurement. Its scale level and the meaning of the data remain often unknown, so that their relevance must be approximated by reliability and validity criteria. Theoretical diversity is considered as one of the main reasons for the lack of consistent and meaningful measures in the field of education. Furthermore many variables in the field of education are not quantifiable.

The main concern of measurement by indicators in education is its ambivalent character. On the one hand it can provide on the descriptive level relevant information and support for political decision-making, on the other hand the «culture of indicators» takes on increasingly features of a normative control system.

Key words

Index, indicator, measurement, PISA, educational management, globalization.

Recibido: 31-03-2017 Aceptado: 02-05-2017

\section{Globalização e Indicadores Educacionais}

Os sistemas educacionais até hoje são mais do que outros subsistemas sociais (economia, ciência) caracterizados pelas tradições culturais de cada nação inclusive as suas contradições que resultam do seu desenvolvimento histórico. Porém, apesar de todas as diferenças e particularidades existentes, o processo da globalização exerce impactos também sobre a realidade educacional. Organizações internacionais, tais como EU, OECD, UNESCO, Banco Mundial, estendem cada vez mais sua esfera de influência às políticas educacionais nacionais. Desse modo, a relação entre estado nacional e sistema educacional está em processo de mudança e um regime de educação internacional está emergindo (Parreira do Amaral, 2011).

Devido à importância crescente do denominado capital humano nos sistemas modernos de produção, está desenvolvendo-se um mercado global de serviços educacionais, cujo volume está chegando a vários bilhões de dólares segundo dados do Banco Mundial. A questão não é apenas se em certos setores a iniciativa privada pode ou até deve complementar a oferta pública, a questão é se a educação deve se converter em um serviço a ser vendido como qualquer outra mercadoria. Esta discussão se desencadeou a partir das regulações da OMC e do GATS e as consequências desta privatização e comercialização até agora são pouco conhecidas. Mas sem dúvida, no caso de uma abertura dos mercados nacionais abrangendo todos os setores de serviço se trataria de um novo nível de internacionalização que terá amplas repercussões nas condições nacionais da educação pública.

A crescente concorrência internacional na qual a educação representa de acordo com a declaração do Conselho Europeu Declaração de Lisboa (2000) um fator importante, exerce uma pressão enorme sobre os sistemas educacionais em direção a uma estandardização de estruturas escolares e conteúdos curriculares. Globalização significa também na área educacional estandardização, significa parâmetros estáveis de qualidade, indicadores quantitativos, normas e procedimentos, competências definidas consideradas como sendo relevante no contexto da concorrência internacional e finalmente accountability. A 
manifestação mais óbvia deste desenvolvimento são os sistemas de indicadores educacionais como, p.ex., o sistema da OECD (2016a) que abrange 115 indicadores de diversas áreas (anos escolares, taxas de escolarização, estruturas e organização escolar, financiamento) para todos os membros da OECD e diversos países associados. Junto às avaliações dos conhecimentos e competências dos alunos ao nível internacional, se desenvolveu deste modo um regime poderoso através do qual a globalização está chegando nas escolas no mundo inteiro.

A mais conhecida destas avaliações é o «Programa Internacional de Avaliação dos Estudantes» (PISA). No primeiro estudo PISA no ano 2000 participaram 32 países, a grande maioria deles membros da OECD. No estudo atual (OECD, 2016b) já participaram 72 países sendo 37 fora da OECD entre eles nove da América Latina e dez do mundo islâmico. Isso comprova que esta comparação tem assumido uma dimensão global sendo um produto das novas relações de concorrência internacional e ao mesmo tempo uma manifestação da integração avançada da sociedade mundial. No final desta cadeia de internacionalização se encontram os alunos, os professores das escolas, os funcionários, todos que são envolvidos na base do sistema de ensino. Ninguém nunca os perguntou se eles querem participar neste tipo de avaliação, e quais são suas vantagens em participar.

PISA e outras avaliações internacionais, completadas por avaliações nacionais estão estreitamente vinculadas ao conceito da qualidade da educação escolar. Embora os agentes promotores de PISA evitem interpretar os resultados dos testes como indicador direto para a qualidade do ensino de um país ou mais ainda, de um sistema educacional em geral, na discussão internacional prevalece esta interpretação. No Brasil, p.ex., o Ministério da Educação (MEC) formulou de forma muito clara a relação entre qualidade de educação e indicadores a fim de medi-la.

Ideb é o Indice de Desenvolvimento da Educação Básica,... formulado para medir a qualidade do
aprendizado nacional e estabelecer metas para a melhoria do ensino. O Ideb funciona como um indi-
cador nacional que possibilita o monitoramento da qualidade da educação pela população por meio de
dados concretos, com o qual a sociedade pode se mobilizar em busca de melhorias. Para tanto, o Ideb
é calculado a partir de dois componentes: a taxa de rendimento escolar (aprovação) e as médias de
desempenho nos exames aplicados pelo Inep. Os indices de aprovação são obtidos a partir do Censo
Escolar, realizado anualmente.

A reflexão sociológica crítica referente ao uso e abuso de indicadores está focalizando-se predominantemente ao aspecto filosófico, à noção dominante do conceito do indicador e sua função controladora, a elaboração de novos e melhores indicadores e finalmente, seu caráter normativo que afeta cada vez mais as políticas nacionais na esfera econômica, social e educacional (Beltrán e Villar, 2010). Entretanto, menos atenção recebe a questão fundamental, se construtos tais como qualidade educacional, progresso social, bem estar, ou exclusão/inclusão são realmente mensuráveis ou se os indicadores simplesmente geram artefatos matemáticos-estatísticos que sugerem certezas que não existem. Uma breve revisão dos conceitos de medição, de indicador e de índice pode servir para aproximar-se a uma resposta tentativa desta questão controvertida.

\section{Medição e Indicadores}

Historicamente e metodologicamente a medição é uma base do progresso da ciência. No entanto, antes de medir é mister de esclarecer a questão básica, se o fenômeno a ser medido é realmente mensurável. A solução deste problema é o objetivo central de cada teoria de medição que conecta, de uma forma ou a 
outra, a realidade com os dados. Falando hoje em dia de teoria de medição se refere à teoria representacional de medição ${ }^{2}$ que concebe medição como uma atribuição de números a objetos ou eventos de tal maneira que as estruturas do conjunto empírico (E) são representados por um conjunto numérico (Z) de forma homomórfica respectivamente isomórfica $(\mathrm{f}: \mathrm{E} \rightarrow \mathrm{Z})$. Trata-se não somente de um problema técnico, mas de um problema metodológico, mais ainda epistemológico em quanto se refere à relação entre sujeito e objeto. Sem uma reflexão da base de medição, a análise, a interpretação, e a relevância dos dados sempre estão incertos.

Ninguém duvida da necessidade e da utilidade de medições nas ciências exatas, na economia, na educação física, entre outras. E nosso dia-a-dia está completo de medições, muitas vezes sem serem percebidos conscientemente: horas de trabalho, temperatura de água, salário mensal, peso dos ingredientes na hora de preparar uma comida, ritmo cardíaco, etc. No entanto, nas ciências humanas e sociais (sociologia, psicologia, pedagogia, e outras) existe uma controvérsia veemente com respeito ao processo de quantificação, uma controvérsia que marca uma das divisórias metodológicas mais importantes entre a abordagem quantitativa e qualitativa. É necessário de sublinhar, que medição neste contexto implica a existência de uma propriedade métrica (escala intervalar, escala de razão, escala absoluta) porque medições ao nível nominal (categorias) ou ordinal (postos) se encontram também frequentemente em pesquisas qualitativas, seja de forma explícita ou implícita.

Não cabe ao presente artigo de retomar as polêmicas eternas, se as duas abordagens são complementares ou incompatíveis, mas, esboçar as possibilidades e os equívocos das práticas correntes de medição na esfera educacional. Recorda-se, que a mais de 50 anos atrás, Cicourel (1964) expôs convincentemente que a maioria das medições nas ciências sociais não correspondem às exigências axiomáticas ${ }^{3}$ da teoria representacional de medição, mas são mais ou menos arbitrárias (measurement by fiat). Hoje em dia, onde se produzem permanentemente novos índices, indicadores, rankings, escalas, muitas vezes sem base conceitual sólida, as reflexões críticas de Cicourel parecem ser mais atuais e pertinentes de que nunca. Cabe esclarecer que ele nunca foi um adversário fundamental de mensurações per se, mas de mensurações desvinculadas da realidade social e de significado duvidoso. «Let me underscore the fact, that I am NOT opposed to quantification or formalization or modeling, but do not want to pursue quantitative methods that are not commensurate with the research phenomena addressed» (Cicourel, 2004).

Este distanciamento referente ao processo de quantificação tem sua origem metodológica, entre outros motivos, nas severas dificuldades que as ciências sociais encontram na hora de medir (Felbiger, 2010; Pasquali, 2009), nomeadamente:

- A falta de um sistema de unidades internacionalmente reconhecido como existem nas ciências exatas.

- Os conceitos usados são muitas vezes imprecisos, e suas definições não são aceitas de forma unanime.

- Os construtos são complexos e multidimensionais e muitas vezes não diretamente observáveis.

- As medições são vulneráveis a erros sistemáticos e, portanto não alcançam a precisão necessária e desejável.

\footnotetext{
2 As outras duas teoria de medição conhecidas são (1) a teoria operacional e (2) a teoria clássica (Hand, 1996).

3 As relações empíricas tem que salvar os axiomas básicos da identidade, ordem (transitividade e conectividade), e aditividade.
} 
Perante aos problemas expostos, medições representativas stricto sensu dos construtos teóricos são inviáveis nas ciências sociais. Por motivos pragmáticos se observam em vez dos verdadeiros construtos (variáveis latentes), uma série de indicadores (variáveis manifestas) dos quais se supõe que estes estão em uma relação estreita com o construto que interessa (latino: indicare). Como Rost (2005:6) destacou, nas medições das ciências exatas, o instrumento de medição (p.ex. um termómetro) permite diretamente a leitura do escore da variável em questão. Nas ciências sociais, contudo, há uma diferença fundamental entre conceito medido (p.ex. satisfação com a vida) e indicadores observáveis (p.ex. respostas a uma ou mais perguntas). A maneira como chegar dos indicadores a um escore para o conceito é justamente o objeto dos modelos de medição.

Deste modo, p.ex., a variável «anos escolares» é considerada como indicador para o nível de «educação formal» de uma pessoa, a «taxa de conclusão» dos alunos como indicador para «produtividade do sistema universitário», e o BIP per capita, apesar de todas as críticas, como indicador para o bem-estar de uma população.

Geralmente se usa mais de que um indicador para representar determinados aspectos da realidade porque «os fenômenos estudados pelas ciências sociais são demasiadamente complexos para serem interpretados e analisados sob uma ótica unidimensional (Soligo, 2012:14). Muitas vezes, a mensuração por meio de indicadores é um processo multi-level, quer dizer, os próprios indicadores podem resultar da junção de um conjunto de diversos sub-indicadores. Mediante de uma agregação dos escores dos indicadores resultar finalmente um composite indicador, ou melhor: um índice. De acordo com Siche et al., (2007:139), um índice é o valor agregado final de todo um procedimento de cálculo onde se utilizam, inclusive, indicadores como variáveis que o compõem». Exemplos internacionalmente conhecidos são o Índice de Desenvolvimento Humano (IDH) das Nações Unidas, o Índice de Status Econômico, Social e Cultural (ISEC) da OECD, o Índice de Sustentabilidade Ambiental (ESI), e o Índice de Competividade Mundial (ICM) do Fórum Econômico Mundial. Os escores obtidos nos índices, por sua parte, são usados muitas vezes para construir uma escala de ranking, um procedimento que se virou na atualidade em uma das modas mais questionáveis da qual nada e ninguém escapa. Há rankings de tudo: hospitais, universidades, cidades, países; falta somente, como Kaube (2014) comentou ironicamente, um ranking das melhores religiões do mundo 4 .

O problema da transformação de indicadores em escores de um índice consiste obviamente na seleção, na justificativa teórica e na ponderação ${ }^{5}$ dos diversos indicadores. Em princípio o número de indicadores per se é infinito e portanto, a decisão por um indicador ou outro é inevitavelmente o resultado de um processo seletivo. $\mathrm{O}$ universo dos indicadores que refletem um construto sempre representa somente uma amostra deste universo (Pfeiffer e Püttmann, 2011:44). Indicadores são um tipo de filtro, eles selecionam certos aspectos da realidade e eliminam outros. Em consequência, indicadores sempre podem ser objetos de críticas e assim incentivar a busca de indicadores alternativos. Além do mais, eles não são independentes do tempo e do espaço. «Um indicador útil em determinado lugar e época pode não ser proveitoso para outra região, ou até mesmo para própria região em outro momento» (Soligo, 2012:17).

4 Por mais improvável que possa parecer, a origem desta moda se encontra no século dezoito em forma de pontos e rankings para pintores e escritores famosos da época (Spoerhase, 2014).

5 A ponderação dos indicadores é um problema sumamente importante que tem um impacto aos resultados. Diferentes pesos para os indicadores e diferentes modelos de agregação (aditivo, multiplicativo) dos indicadores levam a diferentes escores no índice e em consequência a diferentes posições no ranking. 
Pressuposto que existem indicadores mensuráveis, segue no próximo passo o problema de correspondência, ou seja, a questão como se pode ter certeza que os indicadores realmente medem as propriedades dos objetos/sujeitos que eles pretendem a medir. Na literatura metodológica este problema é abrangido pelo conceito da validade que em termos gerais se refere ao grau da congruência entre indicadores e construto teórico. Conforme Pasquali (2009:994), a validade é tipicamente discutida nas ciências psicossociais. Mas também nas outras ciências humanas, economia, educação, letras, a validade é um problema permanente, enquanto nas ciências exatas normalmente não há necessidade de provar que um instrumento (p.ex. uma balança) mede a propriedade intencionada (a massa do objeto). Em contraste, se um índice de qualidade educacional mede realmente o que pretende, depende do conceito subjacente como será explicado mais a frente. Resumidamente: medições por meio de índices podem ter uma utilidade prática, caso que sejam cuidadosamente construídos e validados. Mas a qualidade informacional dos escores e o nível de escala são desconhecidos e portanto, a interpretação do significado dos escores sempre tem que ser cautelosa. Os diversos procedimentos de comprovar a validade que representam de certo modo nas ciências sociais um substituto para compensar a falta de uma representação estrutural. Entre os procedimentos estatísticos de testar a correspondência entre o conceito teórico e o conceito observável se destacam modelos causais que estabelecem relações entre construto e indicadores que são passíveis a testes empíricos.

A luz destas reflexões se evidencia de forma muito clara que indicadores não são simplesmente uma coleção qualquer de variáveis, mas supostas manifestações observáveis de construtos teóricos cujo objetivo consiste em elaborar um instrumento de medição. Portanto, a seleção das variáveis observáveis e medíveis precisa de uma justificativa teórica, assim como a ponderação dos indicadores na construção do índice. Devido a falta de uma base teórica sólida se usam preferencialmente pesos iguais o que implica que todos os indicadores são considerados mutuamente como substitutos, um pressuposto que, sobretudo no contexto da avaliação educacional é altamente duvidoso.

A diversidade de teorias, às vezes até contraditórias, é um dos motivos principais para a pletora de índices, escalas e ranking que invadem as ciências humanas e as políticas públicas. Por exemplo, Rohwer e Hülsewig (2011:73) relatam que uma comparação de três estudos relevantes a nível profissional sobre a competividade de países mostrou resultados significativamente diferentes de acordo com o enfoque teórico. Na sociologia, psicologia e pedagogia, a confusão no campo teórico é maior ainda. Os indicadores usados muitas vezes são irrefletidos e os instrumentos construídos superficialmente o que leva a resultados sem significado.

\section{Medição da qualidade educacional}

Os problemas da medição mediante de indicadores se podem mostrar de forma exemplar através do construto da qualidade educacional ${ }^{6}$. O conceito «qualidade» se deriva da palavra latina «qualis» o que significa «de tal natureza». Neste sentido, qualidade designa de forma descritiva, certas características, propriedades ou traços de um objeto qualquer. O escalamento da qualidade, ou seja, a construção de um índice para medi-la exige, igual como no caso de outros construtos, indicadores observáveis e mensuráveis. Em caso de produtos e serviços no âmbito econômico, a qualidade se refere (1) aos requisitos (normas) técnicos ou processuais (NBR, ISO) estabelecidos por órgãos nacionais e/ou internacionais;

6 As reflexões a seguir estão limitando-se à educação escolar. Este escola-centrismo é um restrição conceitual, (Beltrán e Aguilés, 2010: 13) mais não afetará os parâmetros básicos do nosso raciocínio. 
(2) à capacidade de satisfazer determinadas exigências, ou necessidades estabelecidas pelo consumidor. Portanto, a qualidade no sentido descritivo não está necessariamente limitada ao resultado, senão pode incluir também aspectos processuais, ou seja, como o produto ou o serviço foi produzido (quality management). De qualquer modo, o consumidor precisa ter parâmetros, conhecimentos e informações, os quais o possibilitam medir e avaliar a qualidade do objeto ou serviço.

Este marco referencial corresponde amplamente aos princípios de uma economia de mercado. $\mathrm{Na}$ esfera educacional se tenta medir a qualidade educacional basicamente por meio de dois indicadores: anos escolares e rendimento dos beneficiados, seus conhecimentos, competências, hábitos, etc. (Beltrán e Villar, 2010:140). Enquanto o primeiro é fácil de medir, a medição dos conhecimentos e habilidades em aplica-los se efetua por testes mais ou menos sofisticados cujos resultados são expressados em escores. Aspectos processuais, ou contextuais não são levados em consideração. Esta operacionalização parece ser uma solução objetiva e teoricamente fundada, porque ninguém pode negar que o objetivo de uma educação escolar consiste em aprender e proporcionar aos alunos conhecimentos e competências necessárias para a vida. Mas a pergunta central, quais são em termos concretos as competências, conhecimentos e valores relevantes para a qualidade da educação ficam abertos. As empresas, as instituições públicas e privadas, os pais, os alunos, os professores, organizações internacionais e outros stakeholder, tem muitas vezes uma visão diferente de que uma educação de boa qualidade.

Como anteriormente mencionado, os indicadores (critérios) para medir a qualidade dependem do marco teórico subjacente e no caso da educação mais ainda da imagem do homem (Menschenbild) e da visão do mundo (Weltbild). Sendo que o universo dos indicadores que refletem um construto, neste caso o construto «qualidade do aprendizado» é infinito e o conjunto de indicadores usado sempre representa somente uma amostra deste universo. Para os empresários o critério relevante é a utilidade da pessoa no processo de produção, para a igreja a vivência com os valores cristãos, para o estado um cidadão integrado à sociedade, para intelectuais críticos a capacidade de resistência contra processos restritivos e o uso da razão critica, e para os adeptos do ideal clássico de «Bildung» o cultivo de si mesmo, a evolução da interioridade do sujeito, a autopoiesis da consciência.

Diante a esta pluralidade, Psacharopoulos (1995), levantou a pergunta, quem define e implementa os indicadores e quais são os objetivos a serem alcançados através dos conhecimento que os indicadores proporcionam? De um certo modo é uma questão de poder o que se mede e quem avalia o que e através de que critérios. Leis são o resultado de discursos públicos e decisões políticas, preços são, pelo menos em mercados eficientes, o resultado de oferta e demanda. Entretanto, conteúdos curriculares e estruturas do sistema educacional são resultados de negociações complexas entre setores administrativos, atores políticos e econômicos, expertos acadêmicos e, como resultado da globalização cada vez mais organizações internacionais tais como a OECD ou o Banco Mundial. Eles implicam controle mediante das avaliações, mas sua legitimidade é duvidosa, porque uma discussão pública quase não existe e dificilmente a realizar porque o assunto é teoricamente complicado e pouco atraente para a mídia e o público em geral.

A situação quanto aos indicadores educacionais se complica sob uma perspectiva sistêmica. Os indicadores usados para medir a qualidade, ou melhor, dito, o performance do sistema são compostos via regra como agregados de indicadores individuais. A maioria deles se incorpora ao modelo internacionalmente reconhecido hoje em dia: Context-Input-Process-Output-Outcome. Os resultados dos mencionados testes nacionais e internacionais, baseados em complexos modelos de medição, como p.ex. o modelo de resposta 
ao item (TRI), o nível de conclusão escolar, as taxas de conclusão nos diferentes níveis, os anos médios de escolaridade etc. são os mais conhecidos indicadores do output. Ultimamente, indicadores referentes à paridade dos gêneros e a equidade social estão ganhando mais consideração. Os números e as taxas de matrículas, os recursos financeiros investidos (professores, materiais, prédios, infraestrutura, etc.) são considerados como input e o outcome são os benefícios individuais e sociais fornecidos pela educação ao largo prazo.

Um indicador importante de processo é a taxa de aprovação durante o ciclo escolar, enquanto indicadores que se referem às metodologias de ensino e os estilos de aprendizagem são abordados raras vezes porque são difíceis de quantificar. Este modelo tem, sem dúvida, um certo valor heurístico, contudo ele não representa um conceito teórico (Wolter, 2008), senão parte simplesmente da definição de certas áreas temáticas ou problemas relevantes (custos, resultados, equidade) as quais em seguida são descritas de forma pragmática através de dados quantitativos disponíveis.

Muitos dos indicadores educacionais entram na construção de conhecidos índices (Índice do Desenvolvimento Humano, Índice de Competividade Internacional, Índice de Habitabilidade Urbana entre outros). Entretanto, um índice composto de diversos indicadores, que podemos denominar «Índice do Desenvolvimento de Educação» até hoje não existe. A falta de um conceito teórico consensual, capaz de guiar a seleção e ponderação de indicadores e o fato que muitos indicadores educacionais não são mensuráveis são apenas dois de diversos obstáculos ${ }^{7}$. Além do mais, os escores de muitos indicadores se devem às condições histórico-culturais do país ou da região, que nenhuma medição ou comparação pode mudar em curto prazo. «Para comprender la realidad educativa de un contexto se ha de conocer sus condiciones de posibilidad, de no ser así, los resultados se naturalizan» (Beltrán e Villar, 2010:140). Se as condições econômicas de um país limitam os gastos por aluno, se a formação dos professores é fraco e a estrutura administrativa ineficiente, é difícil de esperar um rendimento alto. Por isso já vinte anos atrás, Vedder (1997) colocou a pergunta se os resultados de avaliações a nível internacional realmente fornecem um aporte relevante aos países com problemas nos seus sistemas educacionais ou se eles servem somente para comprovar o que estes já sabem, ou seja que se encontram no último quintil da escala internacional pot empo indefinido.

Neste contexto é importante frisar que não existe uma relação linear entre gastos por aluno e rendimento escolar. Uma análise de Pfeiffer (2011:31) revela a presença de uma função logística entre as duas variáveis, o que significa que a partir de certo nível, um aumento dos gastos não leva mais a um aumento significativo do rendimento (curva de saturação). Além do mais, a relação não é determinística, quer dizer, que sempre há países que com gastos modestos alcançam resultados boms, assim como sempre há escolas pobres que por meio de práticas educativas inovadoras conseguem resultados acima da media.

\section{Indicadores para quê?}

Igual às outras ciências, a implementação de indicadores a nível internacional e nacional tem uma face múltipla sendo ao mesmo tempo 1. uma ferramenta teórica indispensável para a pesquisa acadêmica, 2. uma fonte importante de informação para a sociedade civil, 3. um auxilio para desenhar políticas públicas e 4. um instrumento para o controle e o exercício de poder.

1. Para analisar se um sistema educacional garante a igualdade de chances e promove a equidade social no âmbito educacional, precisamos de indicadores mensuráveis que representam estes conceitos.

Um problema específico consiste na possibilidade de influenciar os escores de certos indicadores por motivos políticos, p.ex. as taxas de aprovação. 
Estudos acerca dos impactos do uso de modernas tecnologias de informação e comunicação sobre competências de letramento e satisfação dos alunos na aprendizagem precisam de instrumentos para medir estes construtos. Evidentemente, sobre definições e medições sempre há opiniões divergentes, mas isso é uma característica de cada processo científico. Por outro lado é importante de ter em consciência que nem tudo é mensurável e passível a ser representado por indicadores: os estilos de aprendizagem, os processos extracurriculares, o desenvolvimento da personalidade dos educandos.

2. No tocante à função dos indicadores para a sociedade, vale sublinhar que estes podem funcionar como base informacional para reivindicações justas. Sempre quando existe um financiamento público a consideração de critérios econômicos, entre outros, é indispensável. A sociedade civil tem o direito de saber quais são os destinos e os efeitos dos recursos que o contribuinte destinou ao Estado. Indicadores quantitativos podem contribuir para aumentar a transparência referente ao uso dos recursos, para detectar distorções e inequidades, para subsidiar melhoramentos nas práticas pedagógicas e também para sensibilizar as escolas referentes às suas responsabilidades. Neste sentido é importante e até necessário para um país, saber quais são as competências de seus jovens levando em consideração a magnitude dos recursos investidos e as exigências do mercado de trabalho.

3. Para o setor público em geral e os atores políticos no sistema educacional em especial, indicadores e índices constituem um tipo de informações condensadas, uma ferramenta eficiente para a redução de complexidade, para facilitar a comunicação e a tomada de decisões. Eles fornecem a base para um monitoring continuo e sistemático das condições, processos, resultados e efeitos no sistema educacional, e facilitam o planejamento de processos futuros. Tudo isso é compreensível sob a perspectiva do sistema político, mas não sem risco: situações complexas são simplificadas, uma base teórica dos índices muitas vezes não existe ou fica irrefletido, um alto grau de agregação resulta em índices sem muito sentido, e a preocupação com o posicionamento em rankings se torna uma obsessão. Além do mais, medir e definir metas é uma coisa, achar os caminhos para alcançá-as é outra.

4. O perigo iminente da nova «cultura de indicadores» é a direção e o controle global dos sistemas através da transformação de um conceito descritivo a um conceito prescritivo. Índices e indicadores sobre o status quo tem a função de oferecem informações sobre resultados e problemas persistentes, mas na prática atual, eles se tornam cada vez mais em normas expressando uma aura de autoridade. Evidentemente, cada decisão educacional tem implicações normativas, mas de informações não se pode deduzir normas, nem objetivos. Embora, a OECD sempre enfatize oficialmente que os dados fornecidos não sirvam como mecanismo de controle, mas como um apoio para políticas educacionais dos países, os comentários e discursos dos atores responsáveis da OECD vão muito além de meras recomendações. Uma tríade de lições, críticas e louvores devem servir para exercer pressão aos países que não correspondem aos padrões desejados ${ }^{8}$.

Sem dúvida, há benchmarks consensuais para determinados indicadores educacionais em uma perspectiva global, mas se observa no discurso público que muitas vezes que os dados são compatíveis com objetivos políticos distintos e que os atores os interpretam de acordo com suas posições ideológicas.

As ambivalências da medição da qualidade de educação se tornam óbvias sempre quando se trata de medir a qualidade da educação mediante de testes como PISA ou PIAAC (Programme for the International Assessment of Adult Competencies). Diversos críticos suspeitam a evolução de um novo tipo de

8 Assim, Andreas Schleicher, Diretor na OECD e Coordenador Geral de PISA criticou ano por ano em público a número de estudantes universitários na Alemanha como sendo insuficiente, desconsiderando por completo a estrutura especifica do sistema educacional do país. 
dominação cultural e um empobrecimento dos conteúdos curriculares e dos processos de aprendizagem mediante uma normalização (Meyer e Benavot, 2013) baseado em critérios de demanda dos mercados laborais. Outros esperam que eles podem contribuir para o desenvolvimento de uma base comum de competências internacionalmente reconhecidas, talvez até um espaço de pensamento no sentido de um universo reciprocamente compartido. Uma resposta definitiva até o momento não é possível.

\section{Possibilidades e limites de gestão através de indicadores}

$\mathrm{Na}$ economia e na administração empresarial, a gestão por meio de indicadores quantificáveis e/o índices tem uma longa tradição de acordo com o conhecido dogma: «If you can't measure it, you can't manage it». Em contraste, a tentativa de direcionar sistemas educacionais baseado em conceitos derivados dos princípios da administração empresarial é uma evolução mais recente que resulta da sensação dos atores políticos que nas estruturas e nos processos operativos do sistema educacional como tal e suas unidades (escolas, universidades) existem elementos irracionais e arbitrários, o que exige implementar standards de racionalidade e de gerência, já que não existem mercados para avaliar os produtos e serviços pelos consumidores. Neste contexto, indicadores tem a função de fornecer dados relevantes para avaliar a performance do sistema educacional. Avaliações do tipo PISA, mas também provas a nível nacional, são explicitamente ou implicitamente declarações de desconfiança com o objetivo de exercer controle e pressão para que as escolas se esforcem, proporcionando mais eficácia e eficiência, e finalmente melhores resultados de aprendizagem.

Certamente é um desejo legitimo da sociedade, do estado, dos pais, dos alunos, que as escolas façam um uso racional dos recursos destinados e que os professores assumam sua responsabilidade no processo educativo, o qual é a base para a autonomia e a realização social do ser humano. As grandes interrogações são se medições e avaliações através de sistemas de indicadores, estruturas de controle e accountability realmente produzem conhecimentos que proporcionam decisões racionais com a finalidade de alcançar os objetivos desejados, se as informações quantitativas proporcionadas pelos indicadores resultam em uma melhor qualidade das decisões dos atores na área da politica educacional, ou se eles causam somente turbulências, incertezas e reações irracionais.

Para aproximar-se a este questão é necessário recorrer às análises fundamentais sobre as características especificas de people processing organizations em geral e de escolas em especiais. Já trinta anos atras, Meyer e Rowan $(1977,1978)$ analisaram as características estruturais de organizações educacionais, identificando as formas especificas através das quais eles atuam e legitimam seus processos. O modelo input-processoproduto com o uso de uma tecnologia bem definida, característico para processos de produção material é inadequado para processos de aprendizagem em organizações educacionais, porque a relação entre meios e objetivos é mais complexo e menos determinado. Eles exigem o médium de comunicação entre os educadores e os educandos, quer dizer as intenções e objetivos da educação exigem a cooperação dos alunos. O estado pode e deve colocar a disposição os recursos materiais e pessoais, as escolas podem organizar o ensino e transmitir conhecimentos e normas, mas são os alunos como sujeitos que tem que assimilar os conteúdos. Em consequência, a causalidade entre a intervenção pedagógica e os resultados dos processos de aprendizagem é contingente e as possibilidades de um melhoramento através de uma direção do sistema educacional baseado em sistemas de indicadores e avaliações permanentes são limitadas. Indicadores, avaliações, instrumentos de administração gerencial, benchmarking, concorrência, toda a retórica disseminada sob o sigilo da «nova administração publica» encontra na realidade educacional seus limites 
nas estruturas, na inércia das tradições históricas das escolas e na complexidade dos processos operativos. Aumentar a eficiência e eficácia do sistema educacional mediante de indicadores e métodos gerenciais é uma promessa arriscada e difícil a cumprir como mostram as experiências e resultados insatisfatórios em muitos países do mundo nos últimos anos.

\section{Considerações finais}

A importância crescente e o uso permanente de indicadores e índices na esfera educacional é um fenômeno ambíguo especificamente quando se trata de medir um construto complexo como a qualidade educacional. Um componente deste conceito multi-dimensional são certamente as competências e os conhecimentos dos alunos, mas outras variáveis, as vezes nem quantificáveis, são igualmente importantes. Mais ainda, a qualidade de um sistema educacional depende do contexto sócio-historico, seu nível de desenvolvimento e suas necessidades concretas, que não são necessariamente idênticos para todos os países. Sendo assim, não surpreende que até o momento não existe um índice de desenvolvimento ou progresso educacional internacionalmente reconhecido.

A força sedutiva dos indicadores e índices consiste na sua imagem de objetividade, transparência, plausibilidade e simplicidade. Os indicadores atendem a demanda por informações quantitativas articulados em parâmetros e gráficos que impressionam e que prometam facilitar a tomada de decisões. Mas eles aparentam muitas vezes uma racionalidade e um nível de precisão e validade que de verdade não existe, mais ainda se eles carecem de um sistema teórico elaborado justificando seu uso.

Portanto, a tendência atual de atribuir aos indicadores aspectos normativos é metodologicamente injustificável. Medir é um ato descritivo, avaliar (latino: valere) é um ato normativo e confundindo os dois é um caminho errado.

\section{Referências bibliográficas}

Beltrán, José e Villar, Alícia (2010): “Avaliação em Educação: algumas considerações a respeito dos indicadores”. Educação \& Linguagem, 13 (21), 132-149.

Cicourel, Aaron Victor (1964). Method and measurement in sociology. New York: Free Press of Glencoe.

Cicourel, Aaron Victor (2004). "I Am NOT Opposed to Quantification or Formalization or Modeling, but I Do Not Want to Pursue Quantitative Methods That Are Not Commensurate With the Research Phenomena Addressed". http://www.qualitative-research.net/index.php/fqs/article/ view/549/1186, consultado el 18 de marzo de 2017.

Felbinger, Sabine (2010). Messtheoretische Grundlagen. LMU München: Institut für Statistik. http:// thomas.userweb.mwn.de/Lehre/wise1011/SeminarSozi/SabineFelbinger.pdf, consultado el 02 de marzo de 2017.

Hand, David J. (1996): "Statistics and the theory of measurement". Journal of the Royal Statistical Society, Series $A, 159$ (3), 445-492.

Kaube, Jürgen (2014): “Literarische Bestenlisten. In Genie hatte Goethe achtzehn Punkte”. Frankfurter Allgemeine Zeitung, 8 de octubre de 2014.

Meyer, Heinz-D. e Bemavot, Aaron (eds.) (2013). PIS A, Power, and Policy: the emergence of global governance. Oxford: Symposium. 
Meyer, John W. e Rowan, Brian (1977): "Institutionalized Organizations: Formal Structure as Myth and Ceremony”. American Journal of Sociology, 83 (2), 340-363.

Meyer, John W. e Rowan, Brian (1978). “The Structure of Educational Organizations” en Marshall W. Meyer (ed.): Environments and Organizations. San Francisco: Jossey-Bass.

Ministério de Educação. Ideb - Apresentação. http://portal.mec.gov.br/secretaria-de-educacao-basica/ programas-e-acoes?id=180, acessado em 18 de março de 2017.

OECD (2016a). Education at a Glance 2016: OECD Indicators, OECD Publishing, Paris. http://dx.doi. org/10.1787/eag-2016-en, acessado em 18 de março de 2017.

OECD (2016b). PISA 2015 Results (Volume I): Excellence and Equity in Education, OECD Publishing, Paris. http://dx.doi.org/10.1787/9789264266490-en, acessado em 18 de março de 2017.

Parreira do Amaral, Marcelo (2011). Emergenz eines Internationalen Bildungsregimes? International Educational Governance und Regimetheorie. Münster et al.,: Waxmann.

Pasquali, Luiz (2009): "Psicometria". Revista da Escola de Enfermagem da USP, 43, 992-999. http://www. revistas.usp.br/reeusp/article/view/40416, acessado em 15 de março de 2017.

Pfeiffer, Dietmar K. e Püttmann, Carsten (2011). Einfübrung in die Methoden empirisch-pädagogischer Forschung Hohengehren: Schneider.

Pfeiffer, Dietmar K. (2011): "Daten und Diskurse in der aktuellen Bildungspolitik" en Christian Tarnai (ed.): Sozialwissenschaftliche Forschug in Diskurs und Empirie. Münster, New York: Waxmann.

Psacharopoulos, George (1995): "Evaluation of Education and Training: What room for the Comparative Approach?”. International Review of Education, 40 (1), 5-17.

Radtke, Franz-Olaf (2009): "Evidenzbasierte Steuerung - Der Aufmarsch der Manager im Erziehungs system" en Rudolf Tippelt (ed.): Steuerung durch Indikatoren. Opladen: Budrich.

Rohwer, Anja e Hülsewig, Oliver (2011): “Länderrankings: Zu welchen Ergebnissen kommt die neuere Forschung?” Wirtschaftsdienst, 91 (11), 735-759. DOI: 10.1007/s10273-011-1295-6, acessado em 19 de março de 2017.

Rost, Jürgen (2005): "Messen wird immer einfacher". ZA-Information, 56, 6-7.

Sampieri, Roberto Hernández et al., (2013). Metodologia de pesquisa5. Porto Alegre: Penso

Siche, Raúl et al., (2007): “Índices versus indicadores: Precisões conceituais na discussão da sustentabilidade de países”. Ambiente \& Sociedade, X(2), 137-148.

Soligo, Valdecir (2012): "Indicadores: Conceito e complexidade do mensurar em estudos de fenômenos socias”. Estudos em Avaliação Educacional, 23 (52), 15-25

Spoerhase, Carlos (2014): "Das Maß der Potsdamer Garde. Die ästhetische Vorgeschichte des Rankings in der europäischen Literatur-und Kunstkritik" en Wilfried Barner et al., (eds): Jahrbuch der Deutschen Schillergesellschaft. Berlin: de Gruyter.

Vedder, Paul (1994): “Global Measurement of the Quality of Education: A Help to Developing Countries?”. International Review of Education, 41 (3-4), 259-284. 
Wolter, Andrä (2009): "Hochschulindikatoren in der nationalen Bildungsberichtserstattung” en Rudolf Tippelt (ed.): Steuerung durch Indikatoren. Opladen: Budrich.

\section{Nota biográfica}

Dietmar K. Pfeiffer es Doctor en Ciencias Sociales. Profesor investigador y miembro del Centro Brasileiro de la Universidad de Münster (Alemania). Consultor internacional en las áreas de economía educacional, desarollo institucional y evaluación. Entre sus publicaciones recientes están «Análise de dados verbais» en M.Tavares y R. Jarry R. (Org.) (2015), Metodologias Qualitativas. Curitiba: CRV; «Das Bildungssystem Brasiliens unter besonderer Berücksichtigung des Hochschulwesens» en V. Oelsner y C. Richter (eds.) (2015): Bildung in Lateinamerika. Strukturen, Entwicklungen, Herausforderungen, Münster/New York: Ed. Waxmann. Coautor en «A evasão escolar no contexto da expansão do ensino superior», en M.D. Sobrinho; R. Ennafaa; E. Chaleta (eds.) (2016), La educación superior, el estudiantado y la cultura universitaria. València: Ed. Neopatria. 